\title{
ANALYSIS-BASED 2D DESIGN OF STEEL STORAGE RACKS
}

\author{
K.J.R. RASMUSSEN \& B.P. GILBERT \\ School of Civil Engineering,University of Sydney \\ Building J05 \\ The University of Sydney NSW 2006, Australia \\ k.rasmussen@usyd.edu.au
}

Received (28 December 2009)

Accepted (Day Month Year)

\begin{abstract}
The paper presents a study of the capacities of steel rack frames based on linear analysis (LA), geometric nonlinear analysis (GNA) and geometric and material nonlinear analysis (GMNIA). In the case of linear and geometric nonlinear analyses, the design is carried out to the Australian coldformed steel structures AS/NZS4600. The study includes braced, unbraced and semi-braced frames, and compact and non-compact cross-sections. The paper shows axial force and bending moment paths for geometric and geometric and material nonlinear analyses, and explains the differences observed in the design capacities obtained using the different types of analysis on the basis of these paths. The paper provides evidence to support the use of advanced geometric and material nonlinear analysis for the direct design of steel rack frames without the need for checking section or member capacities to a structural design standard.
\end{abstract}

Keywords: Steel Storage Racks, Australian Standard, Advanced Analysis, Design

\section{Introduction}

Current specifications for steel structures ${ }^{1-3}$ allow the design to be based on "advanced" geometric and material nonlinear analysis. In the Australian Standard AS4100 ${ }^{1}$, inelastic second order effects may be determined by advanced analysis, requiring only the crosssection and connection capacities to be determined according to the Standard. In Eurocode3, Part $1.1^{3}$, and the American Specification (AISC-LRFD) ${ }^{2}$, a similar approach is permitted except that the member interaction strength equations for combined actions are required to be used even when the internal stress resultants are determined from advanced geometric and material nonlinear analyses. In all cases, the cross-section must be compact and members must be fully braced against torsion and lateral buckling.

When first published in 1990, the Australian Standard (AS4100) included provisions for geometric nonlinear elastic analysis (often termed " $2^{\text {nd }}$ order" analysis) as well as geometric and material nonlinear analysis. Commercial software featuring $2^{\text {nd }}$ order analysis was developed soon after and has been employed increasingly in design offices as the basis for structural design over the last 20 years, thus obviating the need for amplification of moments determined by linear-elastic small-displacement (" 1 st order") analysis. It is now common practice in Australia to use geometric nonlinear analysis for design. However, mainstream commercial structural analysis software packages have not 
included geometric and material nonlinear analysis, partly because of (i) the greater complexity of specifying material properties in such analyses and (ii) the requirement to include geometric imperfections and residual stresses, which are generally not defined in structural design standards, and partly because national design standards still require the section or member capacity to be checked, thus effectively negating efficiencies to be gained by using geometric and material nonlinear analysis for direct structural design. In effect, the only benefit to be gained from employing geometric and material nonlinear analysis over geometric nonlinear analysis is that the obtained internal stress resultants are more rationally based. Interestingly however, the recently released Version 2.4.1 of the widely industry-used Australian software package Strand $7^{4}$ includes the capability to analyse structural frames by geometric and material nonlinear analysis as per the method described in Clarke and al. ${ }^{5}$. This capability will stimulate design engineers' interest in using this type of analysis in design, particularly if (i) the design is allowed to be based directly on the nonlinear analysis without an imposed recourse to interaction equations in national standards and (ii) the current scope of geometric and material nonlinear analyses is broadened to include slender cross-sections and non-fully braced members failing by flexure and torsion.

While geometric and material nonlinear analysis has not yet been generally embraced in design practice, research institutions have used advanced analysis finite element packages like Abaqus, Ansys, Nastran, Marc and Lusas for several decades and it is now well established that the behaviour of structural steel frames can be very accurately predicted using advanced analysis, provided all features affecting the behaviour are included in the analysis, notably geometric and material nonlinearities as well as imperfections. The literature features a wealth of articles demonstrating that the structural behaviour of members and systems subject to complex buckling modes, (e.g. local, distortional, flexural and flexural-torsional modes) and/or complex material characteristics can be modeled accurately using advanced finite element software.

In view of these advances, when Standards Australia initiated a review of the Australian Standard for Steel Storage Racks, AS4084:1993 ${ }^{6}$, the Standards committee charged with the review decided to include provisions for designing steel storage racks by advanced analysis. This required an articulation of the features required to be modeled in using geometric and material nonlinear analysis, notably guidance on which imperfections to include and their magnitudes. The draft Standard ${ }^{7}$ acknowledges that the analysis may be based on shell element analysis in order to appropriately model the effects of local and distortional buckling and includes provisions for this type of analysis. It also allows for flexural-torsion buckling of the structural members. The main features of the advances made in the new draft Standard ${ }^{7}$ are summarised in Rasmussen and Gilbert ${ }^{8}$.

The main objective of this paper is to investigate the consistency of using different types of analysis as basis for structural design. Hence, case studies are presented for the design of steel storage racks based on linear-elastic, geometric nonlinear and geometric and material nonlinear analyses. Three different bracing configurations and two distinct cross-sections are considered, including a non-compact section which is subject to distortion of the cross-section in the ultimate limit state. Failure modes involving flexural 
and flexural-torsional buckling are investigated. To reduce the number of parameters, perforations are not included in this study and the frames are assumed to be braced in one direction so as to limit displacements to occur in a single plane, with or without torsion of uprights.

\section{Methods and Scope of Analysis}

The draft Standard ${ }^{7}$ includes provisions for design to be carried out on the basis of the following types of analysis:

- LA Linear (" 1 st order”) Analysis assuming elastic material and small displacements.

- GNA Geometric Nonlinear (" $2^{\text {nd }}$ order”) Analysis assuming large displacements.

- LBA Linear Buckling Analysis assuming linear fundamental path.

- GMNIA Geometric and Material Nonlinear ("advanced") Analysis with Imperfections assuming large displacements and inelastic material properties.

A linear buckling analysis (LBA) may be required when using LA analysis to determine moment amplification factors. The draft Standard distinguishes between two types of GMNIA analysis, namely analyses of frames with compact cross-section (GMNIAc), which may be premised on beam elements, and analyses of frames with noncompact cross-section (GMNIAs) which require shell or plate element discretisation to capture the effects of local and distortional buckling deformations.

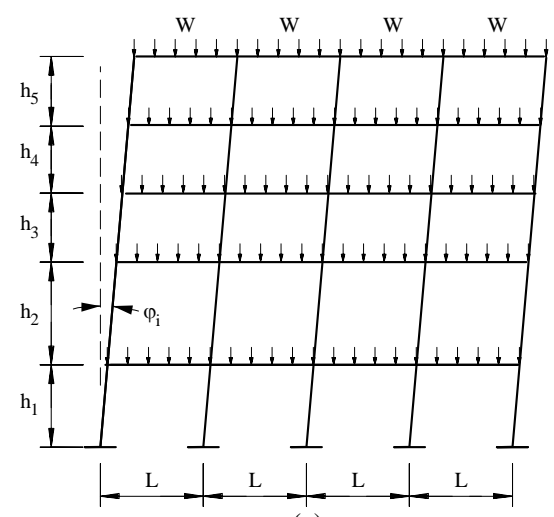

(a)

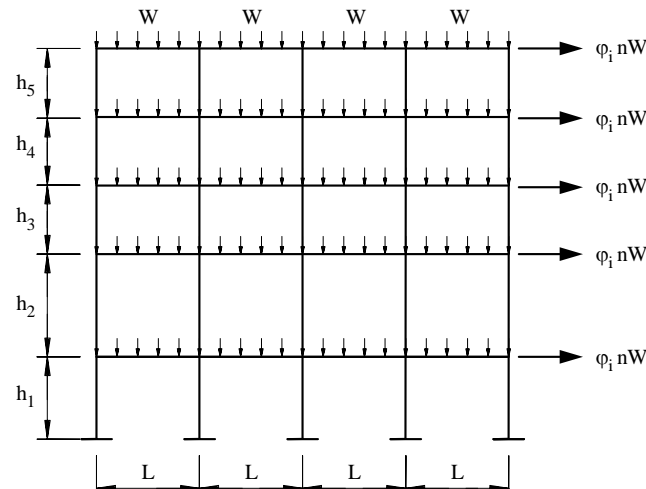

(b)

Figure 1: Frame imperfection, (n is the number of bays), (a) Typical unbraced rack showing initial out-of plumb $\left(\varphi_{\mathrm{i}}\right)(\mathrm{b})$ Equivalent loading system for the unbraced rack

Particular attention is paid to the modeling of geometric imperfections in the draft Standard. Irrespective of the type of analysis, out-of-plumb ("frame") imperfections are modeled by means of equivalent notional horizontal forces, see Fig. 1. In LA, GNA and LBA analyses, this is the only type of imperfection modeled. It is implicit that the effects of out-of-straightness of members between connection points ("member" imperfections) 
and out-of-flatness of component plates of cross-sections ("section" imperfections) are considered by using member (column and beam) strength curves and plate/section (e.g. effective width) strength curves of structural design standards, respectively. In using GMNIAc and GMNIAs analyses, member imperfections must be modeled which can be achieved by (i) superimposing a scaled buckling mode of an equivalent frame with all beam levels restrained horizontally, (ii) reducing the flexural rigidity to $80 \%$ of its elastic value or (iii) off-setting nodes of uprights by an amplitude of $L / 1000$, as shown in Fig. 2 . In using GMNIAs analysis, local and distortional geometric imperfections are also required to be modeled (Fig. 3), e.g. by superimposing scaled local and distortional buckling modes onto the flat section geometry.
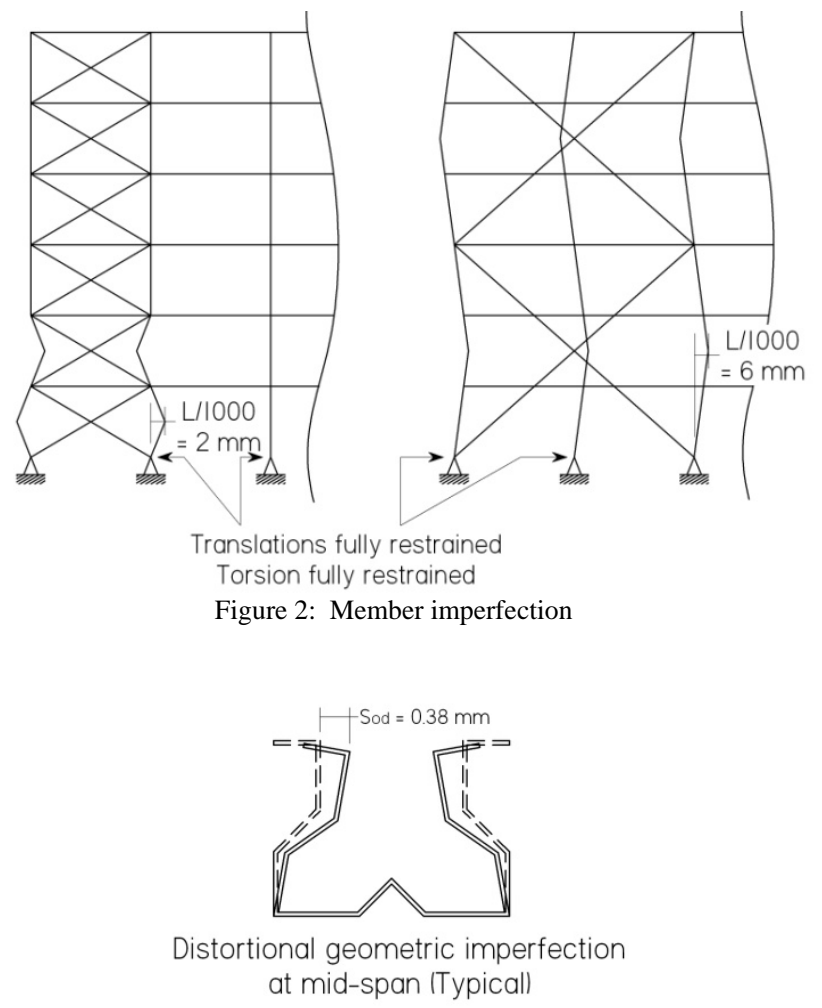

Figure 3: Section imperfection

The draft Standard requires residual stresses to be modeled in GMNIA analyses when significant. The sections considered in this study are assumed to be cold-formed and to have negligible levels of residual stress. Studies ${ }^{4}$ of residual stresses in coldformed SHS reported reductions in ultimate section capacity of $0.2 \%, 0.9 \%, 1.1 \%$ and $7.3 \%$ for four section sizes with a mean reduction of $2.4 \%$. The reduction in ultimate capacity of cold-formed open sections is likely to be even less. Accordingly, residual stresses are not considered in this study. 
The draft Standard allows LBA and GNA analyses to be carried out considering or not considering torsion. In this study, torsion has not been included in LA, LBA and GNA analyses and consequently, the amplification of bending moments in GNA analyses is caused solely by instability related to flexural displacements. As mentioned in the Introduction, displacements are assumed to occur solely in the down-aisle direction.

The GMNIAc analyses are conducted for the distinct cases of torsion and no torsion of the uprights. The GMNIAs analysis based on shell element discretisation allows torsional deformations to develop. However, the cross-aisle displacement of the uprights is fully restrained, as shown in Fig. 4.

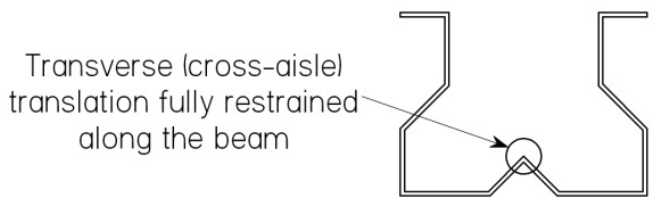

Figure 4: Cross-aisle restraint of uprights

\section{Case Studies}

\subsection{Steel storage frames}

The rack frames considered in this study have the same common overall geometry, consisting of five $3.4 \mathrm{~m}$ wide bays and six beam levels equally spaced $2 \mathrm{~m}$ apart, as shown in Fig. 5. The frames may be unbraced, fully braced or semi-braced, as also shown in Fig. 5. In the semi-braced configuration, the third and upper beam levels are essentially restrained horizontally. Two cross-sections are considered for the uprights, namely a $100 \times 100 \times 6 \mathrm{~mm}$ box section and a rear-flange stiffened rack section with a web width of $110 \mathrm{~mm}$ and a thickness of $1.5 \mathrm{~mm}$, referred to as RF11015, as shown in Fig. 5. In all analyses, the pallet beams and diagonal bracing are assumed to be compact $60 \times 60 \times 4 \mathrm{~mm}$ SHS and compact $30 \times 2 \mathrm{~mm}$ CHS, respectively. The overall geometry and selected crosssections are representative of actual rack frames except that (i) the thickness of the RF11015 section is chosen thinner than what would typically be used in order to accentuate distortional buckling effects and (ii) racks composed of SHS uprights are generally only used in racks with very high pallet loads. The frame is considered to be part of a larger storage rack, which by most racking standards can be designed by considering five bays (or more).

The section constants of the two upright cross-sections are shown in Table 1, where $A$ is the area, $I_{\mathrm{y}}$ the second moment of area about the y-axis, which is the symmetry axis aligned with the cross-aisle direction, $J$ the torsion constant, $I_{\mathrm{w}}$ the warping constant and $\left(x_{0}, y_{0}\right)$ the shear centre coordinates. 
Table 1: Geometric properties of upright cross-sections

\begin{tabular}{lcc}
\hline Property & \multicolumn{2}{c}{ Section } \\
& $\mathbf{1 0 0} \times \mathbf{1 0 0} \times \mathbf{6} \mathbf{~ S H S}$ & $\mathbf{R F 1 1 0 1 5}$ \\
\hline$A\left(\mathrm{~mm}^{2}\right)$ & 2256 & 508 \\
$I_{\mathrm{y}}\left(\mathrm{mm}^{4}\right)$ & $3.33 \times 10^{6}$ & $4.46 \times 10^{5}$ \\
$J\left(\mathrm{~mm}^{4}\right)$ & $5.00 \times 10^{6}$ & 381 \\
$I_{\mathrm{w}}\left(\mathrm{mm}^{6}\right)$ & - & $1.30 \times 10^{9}$ \\
$x_{0}(\mathrm{~mm})$ & 0 & 0 \\
$y_{0}(\mathrm{~mm})$ & 0 & -67.5 \\
\hline
\end{tabular}

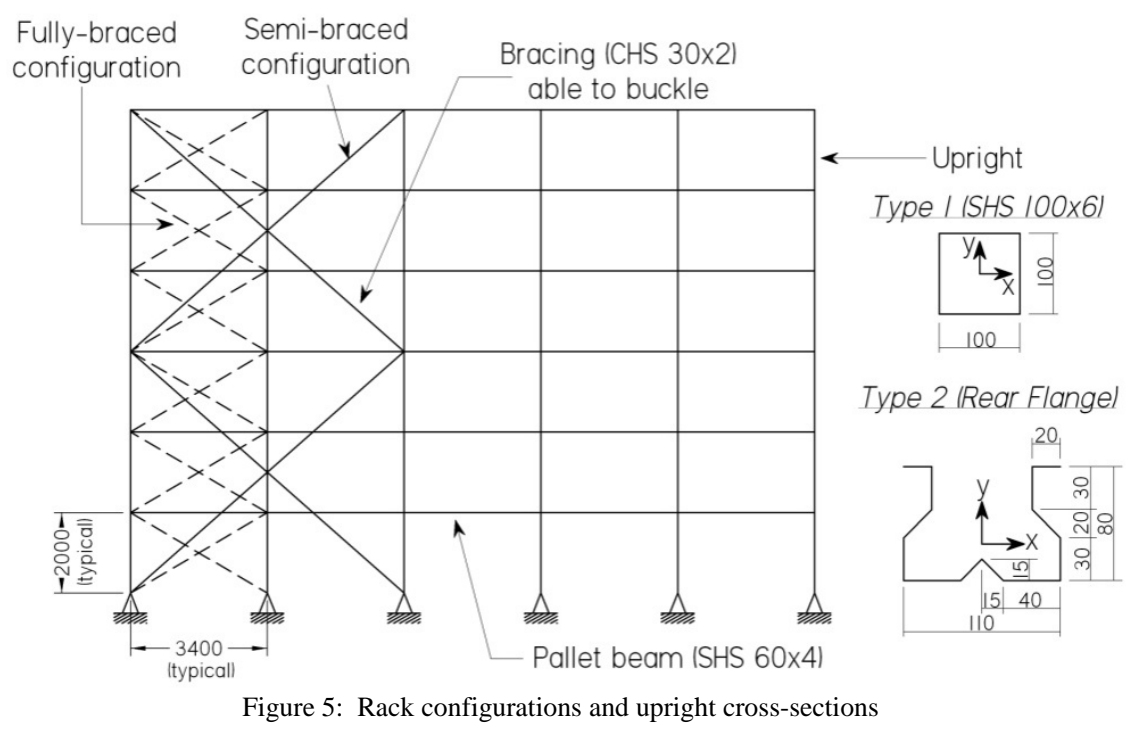

At the base, the uprights are assumed to be simply supported against flexure in the down-aisle direction while prevented against warping. The frame is assumed to be braced against displacements in the transverse (cross-aisle) direction. In the LA, GNA and GMNIAc analyses, the connections between the uprights and pallet beams are assumed to be rigid. The connection between uprights and pallet beams in the GMNIAs analyses is explained in the subsequent section. In practice, the base and upright-to-pallet beam connections are likely to be semi-rigid and there may be great variability in the stiffness of these connections among different manufacturers. The bending moment distributions presented in this paper are thus representative of racks with relatively flexible base connections and relatively rigid upright-to-pallet beam connections. While changing the stiffness of the connections may change to locations of failure in the rack, it is expected that the conclusions reached from this study also apply to frames with semi-rigid connections.

All uprights are assumed to have a yield stress $\left(f_{\mathrm{y}}\right)$ of $450 \mathrm{MPa}$, while all pallet beams and diagonal bracing members are assumed to remain elastic. The engineering 
stress-strain curve for the uprights is assumed to be linear perfectly-plastic in the GMNIA analyses, thus ignoring the effects of strain hardening.

\subsection{Analysis models and results}

The finite element analyses were carried out using the commercial packages Strand $7^{4}$ and Abaqus $^{10}$, as summarised in Table 2.

Table 2: Analysis types and software

\begin{tabular}{ccc}
\hline Analysis & Torsion of uprights & Software \\
\hline LA, LBA, GNA & No & Strand7 \\
GMNIAc & No & Strand7 \\
GMNIAc & Yes & Abaqus \\
GMNIAs & Yes & Strand7 \\
\hline
\end{tabular}

In the GMNIAc analyses which consider torsion of the uprights, both uniform (St Venant) torsion and warping torsion are included. The failure modes in these analyses are dominated by flexural-torsional buckling of the uprights.

The LA, LBA, GNA and GMNIAc (no torsion) analyses use the general purpose beam element of the Strand7 library, while the GMNIAc analysis (torsion) use the beam element B3205 of the Abaqus library for the uprights and beam element B33 for the remaining members. The GMNIAs analyses are carried out using the general purpose shell element of the Strand7 library. In the GMNIAs analyses, the uprights are supported and connected to pallet beams using rigid beam elements, as shown in Fig. 6. The rigid links restrain warping at the base while allowing flexural rotations and applying a concentric reaction force. The rigid links also restrain warping of the web of the uprights but not the flanges at the pallet beam connection points. In effect, the pallet beam connections offer very minor warping restraints to the uprights, while producing a flexurally rigid connection.

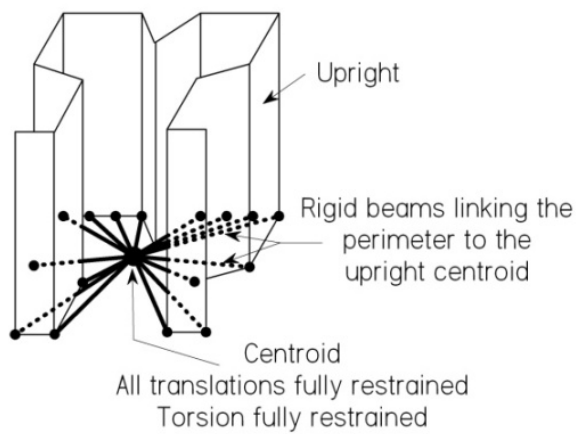

(a)

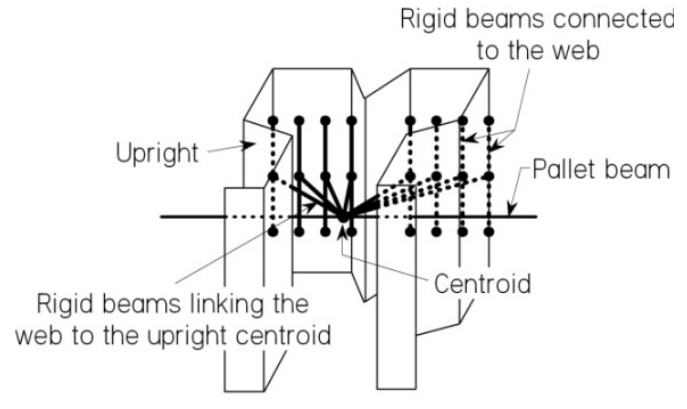

(b)

Figure 6: GMNIAs modeling of base plate support and upright to pallet beam connection, (a) FE model of support at the base and top of upright, (b) FE model of upright to pallet beam connection 
The rack is assumed to be subject to a vertical force $(P)$ at each upright to pallet beam connection point (fully loaded). This modeling of loading is chosen in preference to the actual distributed load on pallet beams because it introduces equal forces in the uprights which is desirable seeing that the frame is assumed to be a sub-part of a larger frame which in the considered fully loaded condition has equal forces in internal uprights. It should be noticed that under full loading, distributed pallet loads do not induce bending moments in internal uprights. According to the draft Standard ${ }^{7}$, notional horizontal forces of $\phi_{\mathrm{s}} V$ are applied at each beam level, where $\phi_{\mathrm{s}}$ is the out-of-plumb and $V$ is the total vertical load applied as the particular level, i.e. $6 P$ for the present study. The out-ofplumb depends on the tolerance grade, as per Table 3, and the type of structural analysis. For all ultimate limit states analyses, including GMNIA analyses, a minimum value of $1 / 500$ is required, while for GNA analysis, a minimum value of $\phi_{s}$ of $1 / 333$ is required.

The analyses reported in this paper are obtained using out-of-plumb values of $1 / 333$ for LA and GNA analyses, and values of 1/333, 1/500 and 1/1000 for GMNIA analyses. Ordinarily, an out-of-plumb value of 1/500 would be used for GMNIA analysis. The additional values of $1 / 333$ and $1 / 1000$ are included in this study to investigate the sensitivity of the frame capacity to out-of-plumb.

Member imperfections are included in the GMNIA analyses of the braced and semibraced frames as per the draft Standard. It is not considered necessary to include member imperfection in the GMNIA analyses of the unbraced frames as the P- $\delta$ (member) moment amplification is negligible compared to the P- $\Delta$ (frame) moment amplification for these frames. According to the draft Standard, the magnitude of the member imperfections is taken as $L / 1000$ where $L$ is the vertical distance between the bracing points, i.e. $L=2 \mathrm{~m}$ for the fully braced frame and $L=6 \mathrm{~m}$ for the semi-braced frame, as shown in Fig. 2.

Table 3: Out-of-plumb ( $\phi$ s) as per draft Standard

\begin{tabular}{ccc}
\hline Tolerance grade & Type of unit load handling equipment & Out-of-plumb $\left(\phi_{\mathrm{s}}\right)$ \\
\hline I & Manually operated equipment guided by & $1 / 500$ \\
II & $\begin{array}{c}\text { Manually operator } \\
\text { electrical or mechanical devices }\end{array}$ & $1 / 750$ \\
III & $\begin{array}{c}\text { Fully automatic operated equipment guided } \\
\text { by electrical or mechanical devices }\end{array}$ & $1 / 1000$ \\
\hline
\end{tabular}

The local and distortional buckling modes and buckling stresses of the RF10015 section are determined using Thinwall ${ }^{11}$. The graph of buckling stresses vs halfwavelength for pure compression is shown in Fig. 7a for the first two buckling modes. Figure $7 \mathrm{~b}$ shows the distortional buckling mode, obtained as the second mode at a halfwavelength of $1000 \mathrm{~mm}$. The distortional buckling stress for pure compression is obtained as $f_{\text {od }}=330 \mathrm{MPa}$. The critical local buckling stress for uniform compression is determined as $f_{\mathrm{ol}}=933 \mathrm{MPa}$. This is substantially higher than the yield stress and so local buckling will not occur before reaching the ultimate capacity. Consequently, local buckling imperfections are not included in the GMNIAs analysis. 
According to the draft standard, the magnitude of the imperfection in the shape of the distortional buckling mode is determined as,

$$
S_{o d}=0.3 t \sqrt{\frac{f_{y}}{f_{o d}}}
$$

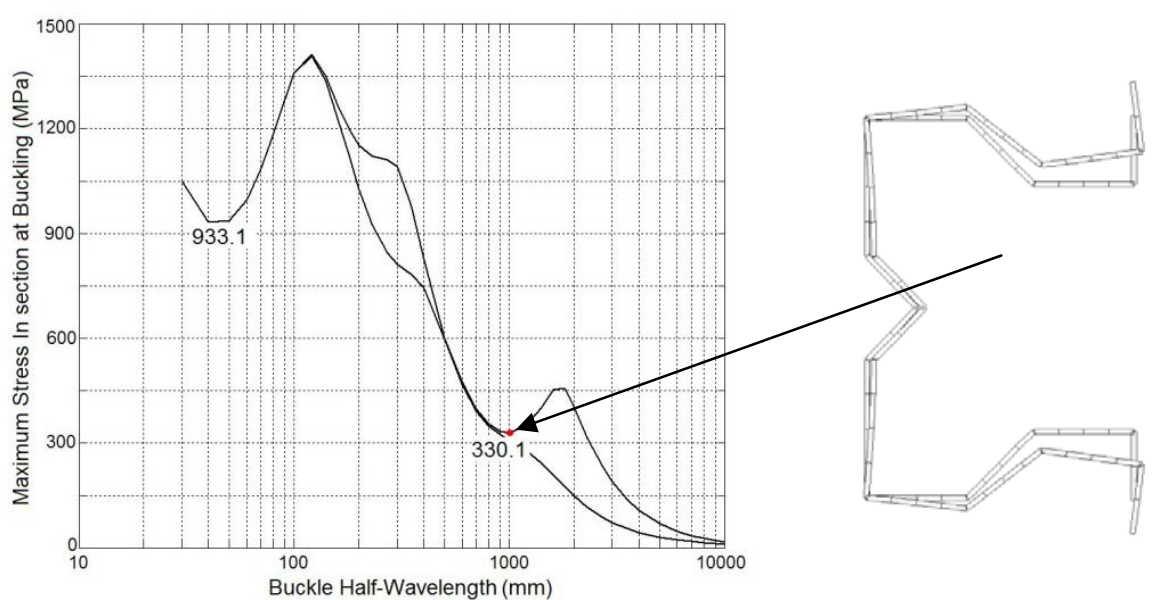

(a)

(b)

Figure 7: Buckling stress vs half-wavelength and distortional buckling mode, (a) Buckling stress vs halfwavelength, (b) Distortional buckling mode

The distortional imperfection is incorporated in the GMNIAs analysis by linearly flaring the flanges between the ends and the centres of the uprights, as exemplified in Fig. 8.

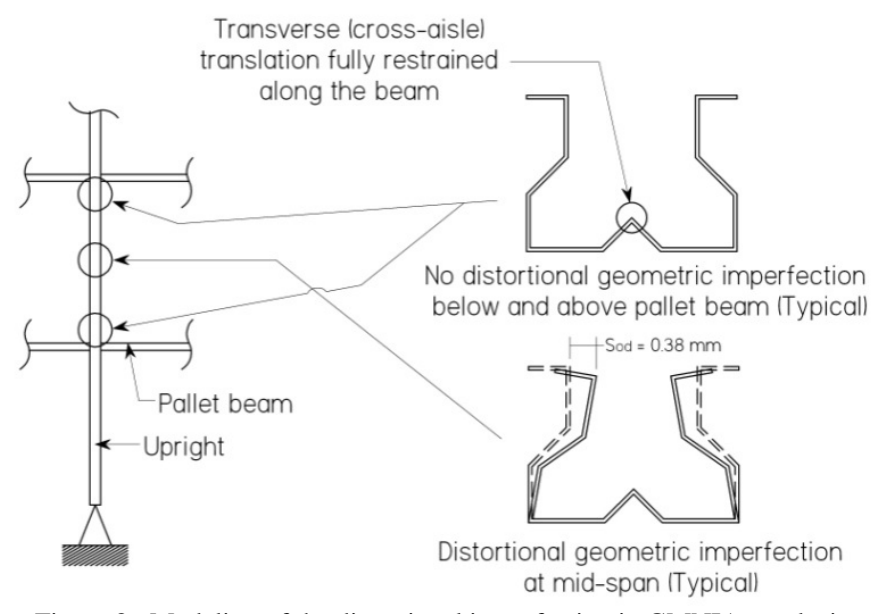

Figure 8: Modeling of the distortional imperfection in GMNIAs analysis 
The buckling loads $\left(P_{\mathrm{c}}\right)$ of the frames are determined for all bracing configurations using an LBA analysis, as summarised in Table 4 . The corresponding buckling modes are shown in the appendices of Rasmussen and Gilbert ${ }^{12}$. The buckling load $\left(P_{\mathrm{cb}}\right)$ of the equivalent fully horizontally restrained frame is also determined by preventing horizontal displacements of each level of the frame. The buckling load of the laterally restrained frame is close to that of the fully braced frame.

Table 4: Frame buckling loads (Pc) in kN.

\begin{tabular}{|c|c|c|}
\hline \multirow[t]{2}{*}{ Bracing arrangement } & \multicolumn{2}{|c|}{ Section } \\
\hline & $100 \times 100 \times 6$ SHS & RF11015 \\
\hline$P_{\mathrm{c}}(\mathrm{kN})$ for unbraced rack & 20.9 & 11.0 \\
\hline$P_{\mathrm{c}}(\mathrm{kN})$ for fully braced rack & 337 & 99.6 \\
\hline$P_{\mathrm{c}}(\mathrm{kN})$ for semi-braced rack & 64.5 & 22.7 \\
\hline Laterally restrained frame $\left(P_{\mathrm{cb}}\right)$ & 342 & 95.4 \\
\hline
\end{tabular}

The LA and GNA analyses produce axial force $(N)$ and bending moment $(M)$ distributions in the frames for given values of applied vertical and horizontal forces. The axial force and bending moment distributions are shown in Figs 9a and 9b for the unbraced rack with $100 \times 100 \times 6 \mathrm{~mm}$ SHS uprights, as determined from an LA analysis. The axial force attains its maximum value between the support and the first beam level, and decreases gradually with increasing beam level. The maximum bending moment is generally found between the floor and the first beam level, and so the critical $(N, M)$ combinations are found for the uprights between the floor and the first beam levels. Similar axial force and bending moment distributions are shown for the fully braced and semi-braced frames in the appendices of Rasmussen and Gilbert ${ }^{12}$.

The frames fail by inelastic flexural buckling of the uprights between the floor and the first beam level in all GMNIA analyses not subject to torsion. When torsion is considered, the overall failure mode is by flexural-torsional buckling of the uprights between the floor and the first beam level and the uprights between the first and second beam level. In the GMNIAs analysis, failure is also associated with distortional buckling, as shown in Figs 10a and 10b for the fully braced frame. The ultimate loads $\left(P_{\mathrm{u}}\right)$ determined from GMNIA analyses are summarised in Discussion. 


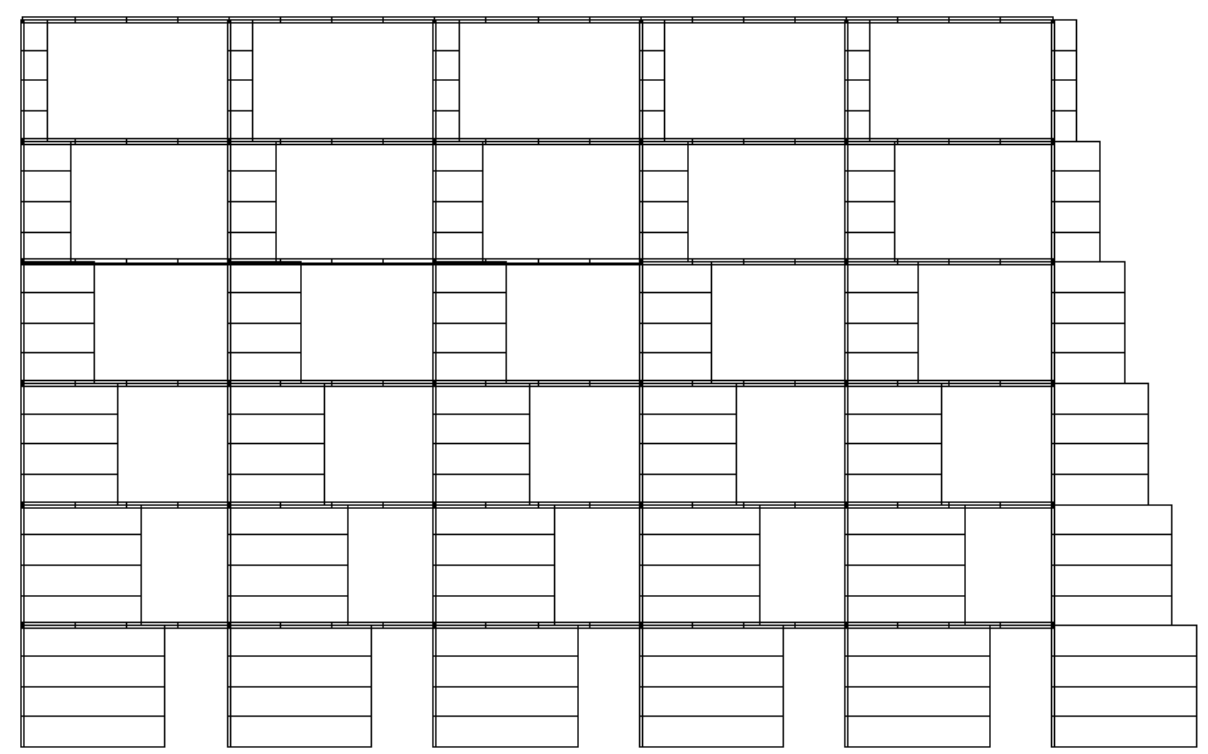

(a) Axial force distribution

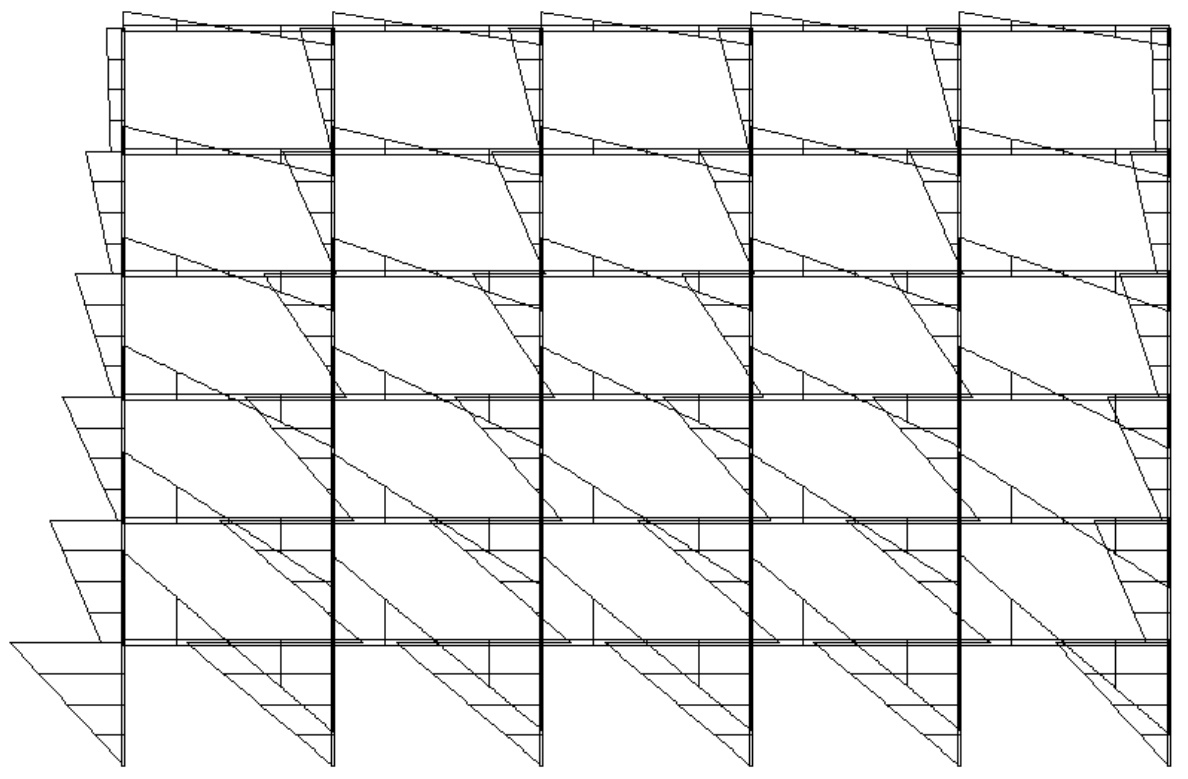

(b) Bending moment distribution

Figure 9: Axial force and bending moment distributions in unbraced rack as determined by LA analysis 


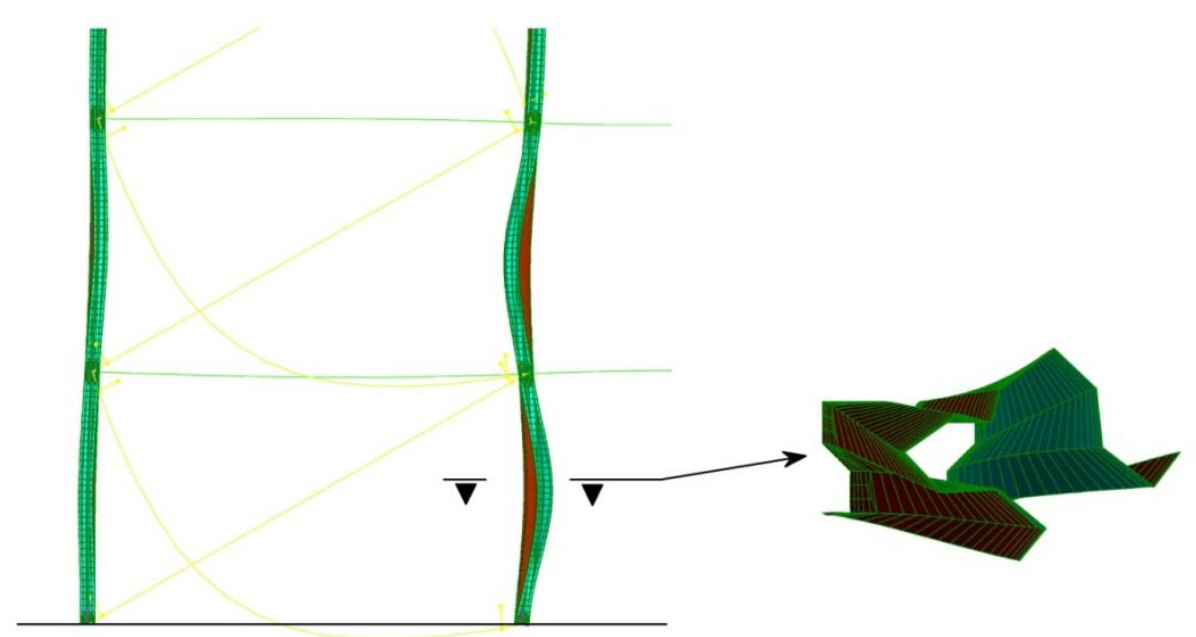

(a) Failure mode of fully braced frame; close-up of first- and second-most uprights near the base. Torsion and distortion of the upright are evident.

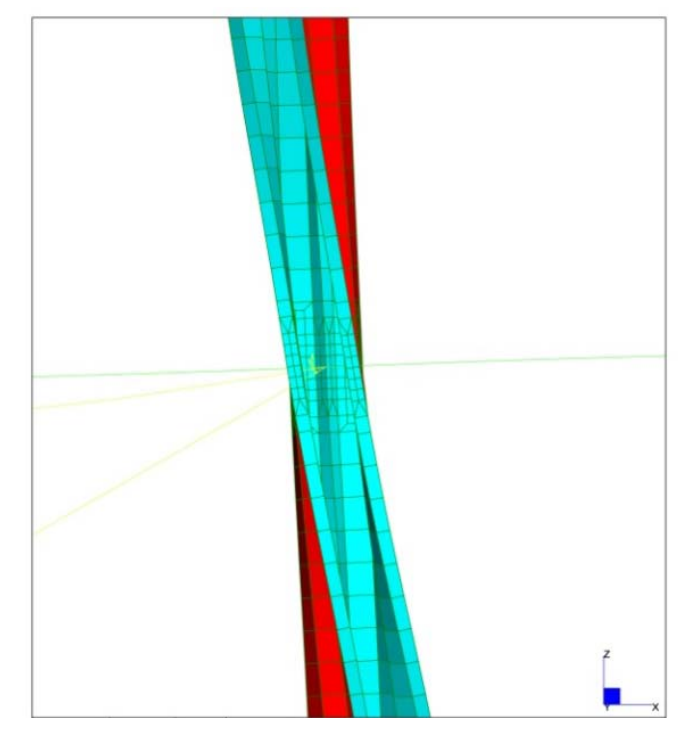

(b) Torsion and warping of critical upright near pallet beam connection point

Figure 10: Failure mode of fully braced frame as obtained from GMNIAs analysis

\subsection{Basis of design}

LA and GNA analyses. The ultimate capacity of the frame $\left(P_{\mathrm{u}}\right)$ is determined by calculating the axial $\left(N_{\mathrm{c}}\right)$ and flexural $\left(M_{\mathrm{b}}\right)$ capacities of the uprights using the Australian Standard for Cold-formed Structures AS/NZS4600:2005 ${ }^{13}$ and requiring the interaction equation be satisfied, 


$$
\frac{N^{*}}{\varphi_{c} N_{c}}+\frac{M^{*}}{\varphi_{b} M_{b}}=1
$$

In eq. (2), $N^{*}$ and $M^{*}$ are the axial force and maximum amplified bending moment in the upright, which are functions of the design load $\left(P_{\mathrm{u}}\right)$, and $\varphi_{\mathrm{c}}=0.85$ and $\varphi_{\mathrm{b}}=0.9$ are resistance factors for compression and bending respectively. For LA analysis, as per the draft Standard, the amplified bending moment is determined as

$$
M^{*}=\frac{M_{L A}^{*}}{\alpha}
$$

where $M_{\mathrm{LA}}^{*}$ is the $1^{\text {st }}$ order moment determined from the LA analysis, and $\alpha$ is the moment amplification factor, calculated as

$$
\alpha=\frac{N_{e}}{N_{e}-N^{*}}
$$

where $N_{\mathrm{e}}$ is the buckling load of the upright, as determined from an LBA analysis. It follows that the amplification factor may be calculated as,

$$
\alpha=\frac{P_{c}}{P_{c}-P_{u}}
$$

where $P_{\mathrm{c}}$ is the buckling load of the frame, see Table 4 , and $P_{\mathrm{u}}$ is the ultimate design load of the frame which is the object of the calculation.

For LA analysis, eqs (2-5) lead to a quadratic equation in $P_{\mathrm{u}}$ while for GNA, increasing values of $\left(N^{*}, M^{*}\right)$ are substituted into the left-hand side of eq. (2) until the equation is satisfied, thus determining the ultimate value of load $\left(P_{\mathrm{u}}\right)$.

The axial $\left(N_{\mathrm{c}}\right)$ and flexural $\left(M_{\mathrm{b}}\right)$ capacities of the uprights are obtained according to the Direct Strength Method included in Section 7 of AS/NZS4600 ${ }^{13}$, and so account for local and distortional buckling. The axial capacity $\left(N_{\mathrm{c}}\right)$ is based on the overall flexural buckling load when torsion is not considered, and the flexural-torsional buckling load when torsion is considered. Because cross-aisle displacements are restrained, flexuraltorsional buckling will not occur as a result of bending and hence, the moment capacity for bending about the y-axis of symmetry $\left(M_{\mathrm{b}}\right)$ is based on the yield moment. The moment capacity is reduced by distortional buckling for the non-compact cross-section.

In determining the axial capacity $\left(N_{\mathrm{c}}\right)$, the effective length $\left(L_{\mathrm{ey}}\right)$ for bending about the $\mathrm{y}$-axis is calculated from the buckling load $\left(P_{\mathrm{cb}}\right.$, see Table 4$)$ of the frame with all beam levels restrained horizontally, as per the draft Standard. As shown in the appendices of Rasmussen and Gilbert ${ }^{12}$, the effective length for bending about the $y$-axis is generally about $90 \%$ of the member length $(L=2 \mathrm{~m})$. In view of the warping restraint at the base and the small warping restraint at the connection points between uprights and pallet beams, the torsional effective length $\left(L_{\mathrm{ez}}\right)$ is determined as $0.7 \mathrm{~L}$ for the lengths of upright 
between the floor and the first beam level, and as $0.9 \mathrm{~L}$ for the uprights between the first and second beam levels. Because of the larger torsional effective length for the uprights between the first and second beam levels, these uprights prove critical in determining the beam-column capacity (i.e. satisfying eq. (2)) in the designs where torsion is considered. GMNIA analyses. The analysis provides the maximum load $\left(P_{\max }\right)$ which can be applied to the frame. Depending on the elements used in the analysis, torsion and cross-sectional distortion are accounted for. According to the draft Standard, the ultimate capacity $\left(P_{\mathrm{u}}\right)$ is determined as,

$$
P_{u}=\varphi_{s} P_{\max }
$$

where $\varphi_{\mathrm{s}}=0.9$ is the system resistance factor.

\section{Discussion}

The ultimate design capacities obtained on the basis of LA, GNA and GMNIA analyses are summarised in Table 5 for the various combinations of bracing arrangement, upright cross-section, and allowance for torsion and cross-sectional instability. The six columns on the right provide the ratios between the capacities based on LA and GNA analyses and the strength obtained using GMNIA analysis, where GMNIA implies GMNIAc when the cross-section is assumed compact and GMNIAs when the cross-section is assumed noncompact. It can be seen that the design capacities predicted on the basis of LA and GNA analyses are close for all bracing configurations and that, on an average basis, the difference between LA and GNA analysis-based capacities and GMNIA-based capacities is $\pm 1 \%$ for $\phi_{\mathrm{s}}=1 / 500$.

However, the capacity ratios are clearly biased towards the bracing configuration. This is brought out in Table 6 which separately lists the averages of the capacity ratios for unbraced, fully braced and semi-braced racks. Evidently, GMNIA analysis-based design capacities are consistently conservative for LA and GNA analysis-based capacities for unbraced frames and consistently optimistic for LA and GNA analysis-based capacities for fully braced frames, irrespective of the out-of-plumb value $\left(\phi_{\mathrm{s}}\right)$. For semi-braced frames, GMNIA analysis-based design capacities are conservative compared to LA and GNA analysis-based capacities when the uprights fail by flexure but may be optimistic when the uprights fail by flexural-torsional buckling. 
Table 5: Design capacities $\left(\mathrm{P}_{\mathrm{u}}\right)$

\begin{tabular}{|c|c|c|c|c|c|c|c|c|c|c|c|c|c|c|}
\hline \multirow{2}{*}{$\begin{array}{l}\text { Upright } \\
\text { cross- } \\
\text { section }\end{array}$} & \multirow[t]{2}{*}{ Bracing } & \multirow{2}{*}{$\begin{array}{c}\text { Compact } \\
/ \\
\text { non- } \\
\text { compact }\end{array}$} & \multirow{2}{*}{$\begin{array}{c}\text { Torsion } \\
\text { of } \\
\text { uprights } \\
\text { in } \\
\text { GMNIA }\end{array}$} & \multicolumn{5}{|c|}{ Design capacity $\left(P_{u}\right)$ in $k N$} & \multirow{2}{*}{$\begin{array}{c}\frac{P_{u, L A}}{P_{u, G M N I A}} \\
\phi_{s}=1 / 1000\end{array}$} & \multirow{2}{*}{$\begin{array}{c}\frac{P_{u, L A}}{P_{u, G M N I A}} \\
\phi_{s}=1 / 500\end{array}$} & \multirow{2}{*}{$\begin{array}{c}\frac{P_{u, L A}}{P_{u, G M N I A}} \\
\phi_{\mathrm{s}}=1 / 333\end{array}$} & \multirow{2}{*}{$\begin{array}{c}\frac{P_{u, G N A}}{P_{u, G M N I A}} \\
\phi_{\mathrm{s}}=1 / 1000\end{array}$} & \multirow{2}{*}{$\begin{array}{c}\frac{P_{u, G N A}}{P_{u, G M N I A}} \\
\phi_{s}=1 / 500\end{array}$} & \multirow{2}{*}{$\begin{array}{c}\frac{P_{u, G N A}}{P_{u, G M N I A}} \\
\phi_{s}=1 / 333\end{array}$} \\
\hline & & & & LA & GNA & $\begin{array}{r}\text { GMNIA } \\
\phi_{\mathrm{s}}=\mathbf{1} / \mathbf{1 0 0 0}\end{array}$ & $\begin{array}{l}\text { GMNIA } \\
\phi_{\mathrm{s}}=\mathbf{1} / \mathbf{5 0 0}\end{array}$ & $\begin{array}{l}\text { GMNIA } \\
\phi_{\mathrm{s}}=1 / 333\end{array}$ & & & & & & \\
\hline \multirow[t]{3}{*}{ SHS } & unbraced & compact & no & 20.2 & 20.0 & 18.7 & 18.5 & 18.2 & 1.08 & 1.09 & 1.11 & 1.07 & 1.08 & 1.10 \\
\hline & braced & compact & no & 113.7 & 113.6 & 136.4 & 134.7 & 131.6 & 0.83 & 0.84 & 0.86 & 0.83 & 0.84 & 0.86 \\
\hline & semi-brac & compact & no & 62.8 & 61.7 & 53.4 & 53.1 & 52.8 & 1.18 & 1.18 & 1.19 & 1.15 & 1.16 & 1.17 \\
\hline \multirow[t]{3}{*}{ RF11015 } & unbraced & compact & no & 9.96 & 9.84 & 9.58 & 9.32 & 9.09 & 1.04 & 1.07 & 1.10 & 1.03 & 1.06 & 1.08 \\
\hline & braced & compact & no & 27.3 & 27.3 & 31.5 & 31.1 & 30.6 & 0.87 & 0.88 & 0.89 & 0.87 & 0.88 & 0.89 \\
\hline & semi-brac & compact & no & 21.1 & 19.8 & 17.9 & 17.7 & 17.6 & 1.18 & 1.19 & 1.20 & 1.11 & 1.12 & 1.13 \\
\hline \multirow[t]{3}{*}{ RF11015 } & unbraced & compact & yes & 9.59 & 9.49 & 9.51 & 9.26 & 9.00 & 1.01 & 1.04 & 1.07 & 1.00 & 1.02 & 1.05 \\
\hline & braced & compact & yes & 15.3 & 15.3 & 19.3 & 19.1 & 19.0 & 0.79 & 0.80 & 0.81 & 0.79 & 0.80 & 0.81 \\
\hline & semi-brac & compact & yes & 15.0 & 15.0 & 16.8 & 16.7 & 16.6 & 0.89 & 0.90 & 0.90 & 0.89 & 0.90 & 0.90 \\
\hline \multirow[t]{3}{*}{ RF11015 } & unbraced & non-comp & yes & 9.30 & 9.16 & 7.88 & 7.48 & 7.29 & 1.18 & 1.24 & 1.28 & 1.16 & 1.22 & 1.26 \\
\hline & braced & non-comp & yes & 15.3 & 15.3 & 18.4 & 18.2 & 18.0 & 0.83 & 0.84 & 0.85 & 0.83 & 0.84 & 0.85 \\
\hline & semi-brac & non-comp & yes & 14.9 & 14.9 & 14.9 & 14.8 & 14.8 & 1.00 & 1.01 & 1.01 & 1.00 & 1.01 & 1.01 \\
\hline Average & & & & & & & & & 0.99 & 1.01 & 1.02 & 0.98 & 0.99 & 1.01 \\
\hline
\end{tabular}


Table 6: Design capacities $\left(\mathrm{P}_{\mathrm{u}}\right)$ for each bracing configuration

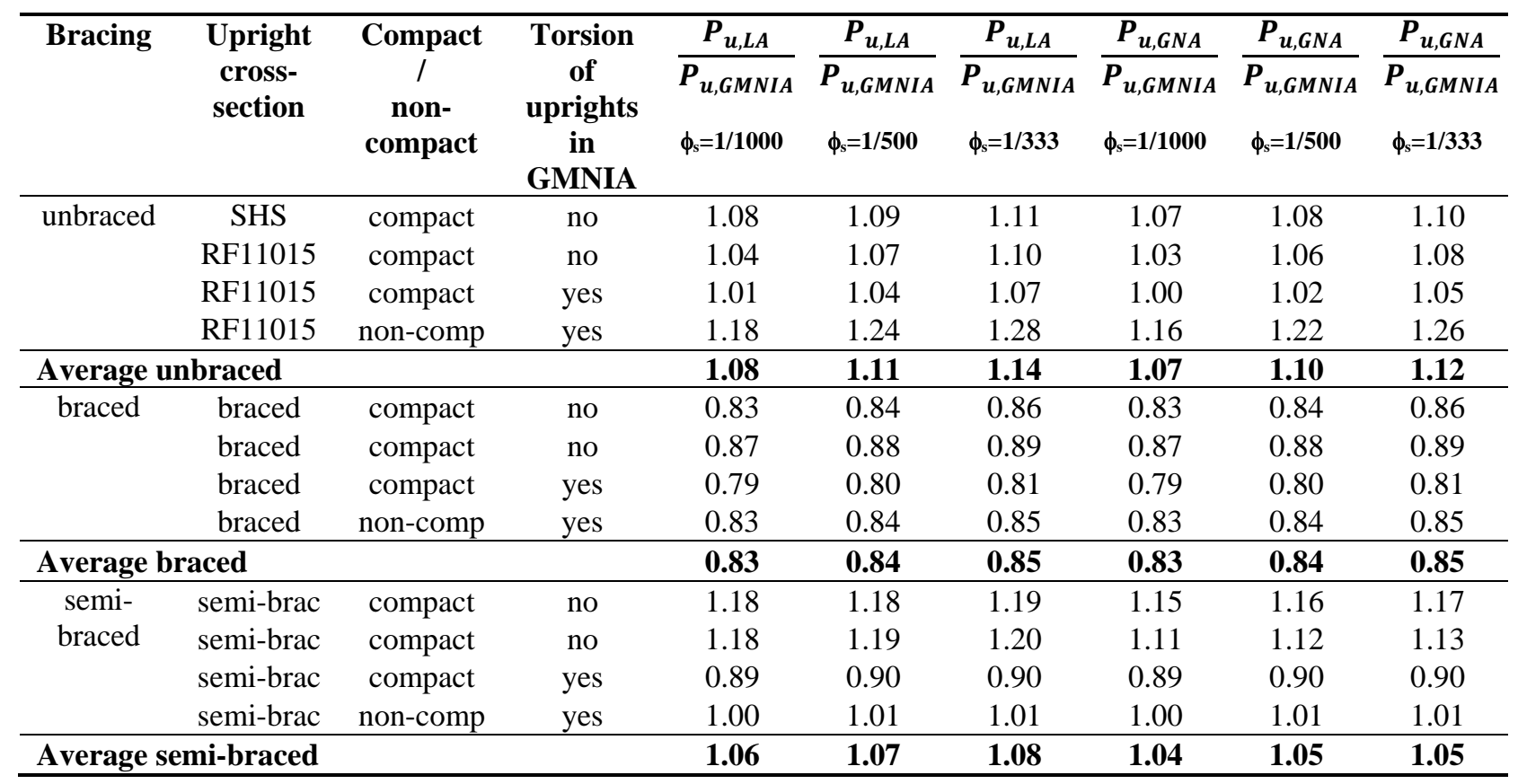

The capacity of the braced rack frames is largely governed by the axial capacity of the uprights, i.e. the $N^{*} / \varphi_{\mathrm{c}} N_{\mathrm{c}}$-term dominates the left-hand side of eq. (2). To investigate the cause of the optimism of the GMNIA analysis-based design capacities for braced frames, a single concentrically loaded box-section upright with an imperfection of $L / 1000$ at the centre is analysed using GMNIAc analysis. The column length $(L)$ is taken equal to the effective column length based on an LBA analysis, i.e. $L=1.83 \mathrm{~m}$, producing an ultimate load $\left(N_{\mathrm{u}}\right)$ of $935 \mathrm{kN}$ and hence a design value of $\varphi_{\mathrm{s}} N_{\mathrm{u}}=841 \mathrm{kN}$. This compares with the column strength design value obtained using AS/NZS4600 of $\varphi_{\mathrm{s}} N_{\mathrm{c}}=701 \mathrm{kN}$, where $N_{\mathrm{c}}=825.7 \mathrm{kN}$ and $\varphi_{\mathrm{c}}=0.85$. Thus, the axial design capacity obtained using GMNIA analysis is higher than that obtained using AS/NZS4600, which is partly because the system resistance factor $\left(\varphi_{s}=0.9\right)$ is higher than the column resistance factor $\left(\varphi_{c}=0.85\right)$, and partly because the nominal strength determined using GMNIA analysis is higher than the design strength obtained using the column strength curve in AS/NZS4600. The latter result may, in part, be a consequence of the omission of residual stresses in the GMNIA analysis model.

To investigate the effect of bending moments on the strength of rack frames, the $\left(N^{*}, M^{*}\right)$-values obtained from the GNA and GMNIAc analyses of the braced, unbraced and semi-braced frames with box section uprights are shown in Fig. 11 and compared with the linear interaction strength curve specified in AS/NZS4600. The following conclusions can be drawn from the figure:

- $\quad$ The bending moment in the critical upright $\left(2^{\text {nd }}\right.$ upright from the left between the floor and the first beam level) of the braced frame is negligible in the GNA analysis (see Figs 11a and 11b) and smaller than in the GMNIAc analysis in 
which it is amplified by member imperfections. The axial capacity as obtained from GMNIAc analysis is insignificantly reduced by the presence of a bending moment in the braced frame, implying that the interaction curve determined by GMNIAc analysis is not linear in the high axial force region; a well-known result for compact I- and rectangular hollow sections, e.g. see ${ }^{14}$.

- $\quad$ The $\left(N^{*}, M^{*}\right)$-curves are highly non-linear for the unbraced frames. As shown in Fig. 11c, the bending moment increases rapidly as the load $(P)$ approaches the buckling load of the frame $\left(P_{\mathrm{c}}=20.9 \mathrm{kN}\right.$, see Table 4$)$ and, in effect, the design load $\left(P_{\mathrm{u}}\right)$ is governed by the elastic buckling load. Because this is not factored down by a resistance factor, the design capacities based on LA and GNA analyses are higher than those based on GMNIAc analysis, which are always reduced by a system resistance factor $\left(\varphi_{s}\right)$ irrespective of the mode of failure. This explains why the GMNIAc analysis-based design capacities shown in Tables 5 and 6 are conservative compared to LA and GNA analysis-based design capacities for unbraced frames.

It can be seen from the averages shown in Table 6 that for braced and semi-braced frames, the difference in the design capacities based on LA and GNA analyses is of the order of $1 \%-2 \%$ for out-of-plumb values varying from $1 / 1000$ to $1 / 333$. For unbraced frames, the design capacities based on LA and GNA analyses change by $6 \%$ and $5 \%$, respectively, for out-of-plumb values varying from $1 / 1000$ to $1 / 333$; implying a modest dependency on the out-of-plumb. 


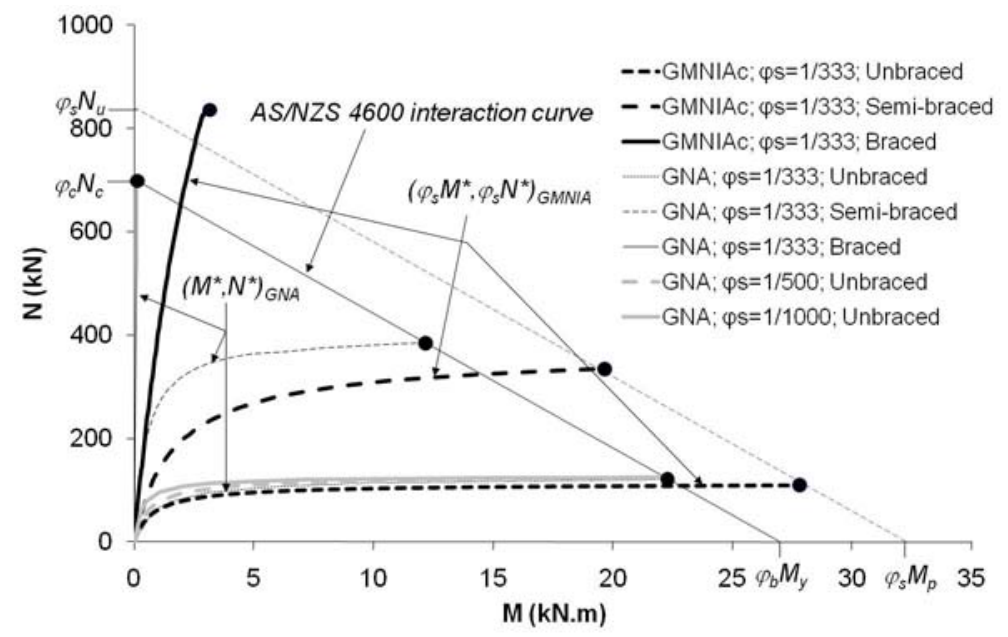

(a) Results for braced, unbraced and semi-braced frames

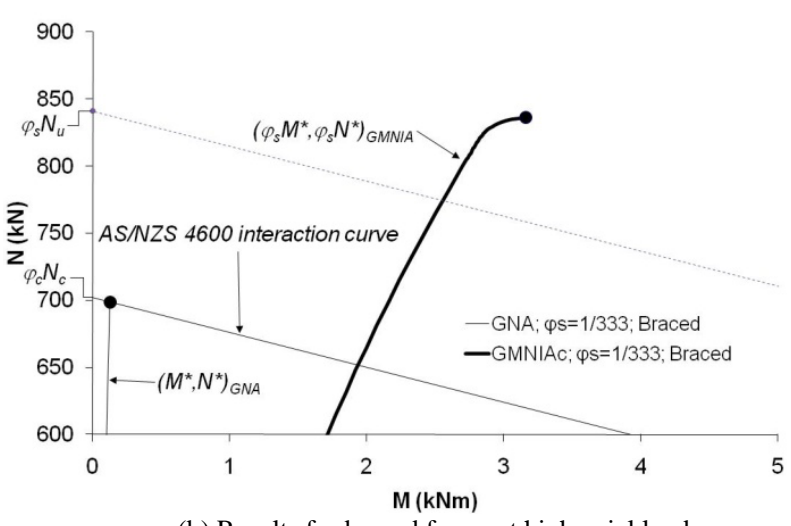

(b) Results for braced frame at high axial loads

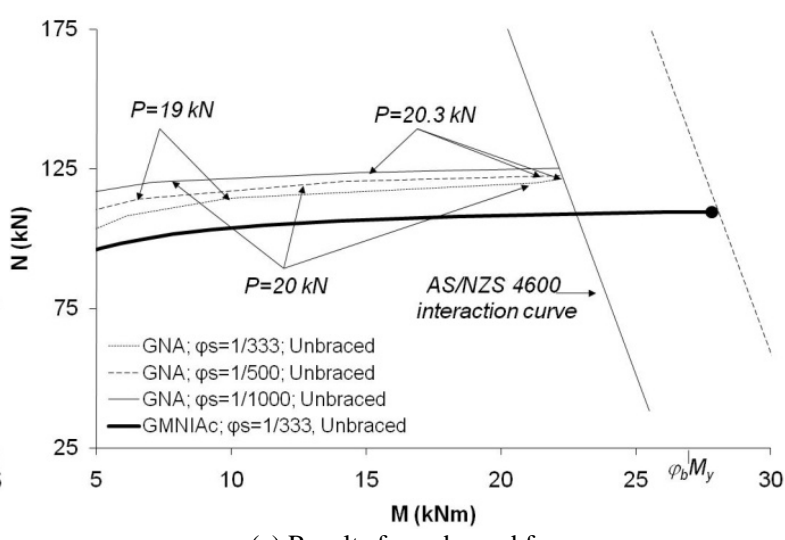

(c) Results for unbraced frame

Figure 11: (N,M)-paths for GNA and GMNIA analyses for braced rack frame.

\section{Conclusions}

This paper presents a comparison of the design capacities of steel rack frames based on linear analysis (LA), geometric nonlinear analysis (GNA) and geometric and material nonlinear analysis (GMNIA). When based on LA and GNA analyses, the design is carried out to the Australian cold-formed steel structures AS/NZS4600. The study includes braced, unbraced and semi-braced frames. It is shown that,

- $\quad$ LA and GNA analyses produce nearly the same design capacities irrespective of the bracing configuration. 
- $\quad$ On average, considering all bracing configurations, the design capacities based on LA and GNA analyses are within 1\% of those determined using GMNIA analysis.

- $\quad$ GMNIA-based design is conservative for unbraced frames while optimistic for braced frames compared to design capacities based on LA and GNA analyses.

- The design capacity is insignificantly affected by out-of-plumb for braced and semi-braced frames, while moderately affected for unbraced frames, for which an increase in out-of-plumb from $1 / 1000$ to $1 / 333$ results in an average decrease in capacity of the order of $5 \%$.

- $\quad$ Flexural-torsional buckling is shown to significantly reduce the design capacity in the case of rear-flange uprights subject to high axial forces.

- The rear-flange section is subject to distortional buckling. The GMNIA analysis-based design capacities are more significantly reduced than predicted by the Direct Strength Method incorporated in AS/NZS4600.

The study provides evidence to show that the structural design of steel rack frames may be based on advanced material and geometric nonlinear analyses. Such GMNIA analyses obviate the need for checking the section and/or member capacities to a structural standard. The study includes compact and non-compact sections and members which fail by flexural as well as flexural-torsional buckling.

The study ignores perforations for the sake of simplicity. It would be of interest to extend the study to include compact and slender cross-sections with perforations. Such study will require the availability of stub column tests in order to apply design standards for steel storage racks in combination with LA and GNA analyses. In using GMNIAs analysis, while modern preprocessors are capable of generating shell element discretisations of perforated sections at relative ease, the number of degrees of freedom will increase and require greater computational capability.

\section{References}

1. AS4100, Steel Structures, AS4100, Standards Australia: Sydney (1998)

2. AISC, Specification for Structural Steel Buildings, ANSI/AISC 360-10, American Institute of Steel Construction: Chicago (2010)

3. EN1993-1-1, Eurocode 3: Design of steel structures Part 1-1: General rules and rules for buildings, European Committee for Standardisation: Brussels (2005)

4. Strand7, Theoretical Manual, Version 2.4, Sydney: G\&D Computing (2009)

5. Clarke, M.J., Bridge, R.Q., Hancock, G.J., and Trahair, N.S., Advanced analysis of steel building frames, Journal of Constructional Steel Research 23(1-3) (1992) 1-29.

6. AS4084, Steel Storage Racking, Standards Australia: Sydney (1993)

7. DB062/B0816, Steel Storage Racking, Standards Australia: Sydney (2011)

8. Rasmussen, K.J.R. and Gilbert, B.P., Analysis-based design provisions of steel storage racks, School of Civil Engineering, University of Sydney (2011)

9 Key, P.W. and Hancock, G.J., A Theoretical Investigation of the Column Behaviour of Cold-Formed Square Hollow Sections, Thin-Walled Structures, 16 (1993) 31-64

10. Hibbitt, Karlsson, and Sorensen, Abaqus Standard User Manual, Version 6.3-1 (2002) 
11. Papangelis, J.P. and Hancock, G.J., Computer Analysis of Thin-Walled Structural Members, Computers and Structures 56(1) (1995) 157-176

12. Rasmussen, K.J.R. and Gilbert, B.P., Analysis-based 2D design of steel storage racks, Research Report No. 908, School of Civil Engineering, University of Sydney (2010)

13. AS/NZS4600, Cold-formed Steel Structures, AS/NZS 4600, Standards Australia: Sydney (2005)

14. Trahair, N.S., Design strengths of steel beam-columns, Canadian Journal of Civil Engineering, 13(6) (1986) 639-646 